\title{
Flora do Espírito Santo: Ericaceae
}

\author{
Flora of Espírito Santo: Ericaceae
}

\author{
Gerson Oliveira Romão ${ }^{1,3}$, Andressa Cabral $^{2}$ \& Luiz Menini Neto ${ }^{2}$
}

\begin{abstract}
Resumo
Apresenta-se um estudo taxonômico de Ericaceae no estado do Espírito Santo, Região Sudeste do Brasil, incluído nos domínios da Floresta Atlântica. Ericaceae está representada no Brasil por 12 gêneros e 98 espécies, com distribuição predominante nos campos rupestres e campos de altitude da Região Sudeste. No Espírito Santo, estão registradas 11 espécies pertencentes a três gêneros - Agarista (duas spp.), Gaultheria (duas spp.) e Gaylussacia (sete spp.), das quais são endêmicas da Floresta Atlântica Agarista revoluta, Gaultheria eriophylla var. eriophylla, Gaultheria serrata, Gaylussacia fasciculata e Gaylussacia caparoensis, esta última incluída na categoria "Em Perigo" (EN) no Livro Vermelho da Flora do Brasil. Chaves de identificação, descrições, ilustrações de caracteres diagnósticos e comentários de distribuição geográfica, ecológicos e taxonômicos das espécies são apresentadas.
\end{abstract}

Palavras-chave: biodiversidade, flora, Floresta Atlântica, taxonomia.

\begin{abstract}
A taxonomic study of the Ericaceae the Espírito Santo state, Southeastern Brazil, Atlantic Forest domain, is presented. Ericaceae is represented by 12 genera and 98 species in the Brazil, with predominant distribution in the southeastern "campos rupestres" and "campos de altitude". In Espírito Santo, 11 species belonging to three genera are recorded - Agarista (two spp.), Gaultheria (two spp.) and Gaylussacia (seven spp.), of which Agarista revoluta, Gaultheria eriophylla var. eriophylla, Gaultheria serrata, Gaylussacia fasciculata and Gaylussacia caparoensis are endemic to the Atlantic Forest, latter is included in the category "Endangered" (EN) by "Livro Vermelho da Flora do Brasil". Identification keys, descriptions, illustrations of diagnostic characters, and comments of geographic distribution, ecological and taxonomic are provided.
\end{abstract}

Key words: biodiversity, flora, Atlantic Forest, taxonomy.

\section{Introdução}

Ericaceae abrange 124 gêneros e aproximadamente 4.100 espécies (Judd et al. 2008). É uma família de distribuição cosmopolita, ocorrendo principalmente nos terrenos ácidos das regiões temperadas e subtropicais de ambos os hemisférios, mais frequentemente em cadeias montanhosas nos trópicos, sendo caracterizada geralmente pelo hábito arbustivo a arbóreo, folhas simples, alternas e não estipuladas, corola gamopétala e estames epipétalos (KinoshitaGouvêa 1980; Luteyn et al. 1995). Segundo Luteyn (2002), a maioria das Ericaceae neotropicais apresenta ornitofilia como síndrome de polinização, como flores e brácteas não aromáticas com coloração chamativa, corola tubular e presença de disco nectarífero.

Kron et al. (2002), com base em uma análise filogenética utilizando evidências macromoleculares e morfológicas, propôs uma nova classificação reconhecendo oito subfamílias e vinte tribos, com destaque para Ericoideae Link, Monotropoideae Arn. e Vaccinioideae Arn. encontradas na região neotropical.

No Brasil, a família é representada por 12 gêneros e 98 espécies das quais 71 são endêmicas, distribuídas principalmente nas áreas de maiores altitudes nos domínios do Cerrado e Floresta

\footnotetext{
${ }^{1}$ Universidade de São Paulo, Escola Superior de Agricultura Luiz de Queiroz, Depto. Ciências Biológicas, Av. Pádua Dias 11, C.P. 9, 13418-900, Piracicaba, SP, Brasil.

${ }^{2}$ Universidade Federal de Juiz de Fora, Inst. Ciências Biológicas, Campus Universitário, 36036-330, Juiz de Fora, MG, Brasil.

${ }^{3}$ Autor para correspondência: goromao@usp.br
} 
Atlântica, ocasionalmente ocorrendo na Caatinga e Amazônia (Kinoshita \& Romão 2010, BFG 2015). Dentre os representantes cultivados no Brasil, as espécies de Rhododendron L. e Erica L. possuem um alto potencial ornamental e foram introduzidas da Europa e Ásia (Kinoshita \& Romão 2012).

A Floresta Atlântica é considerada um dos principais hotspots mundiais de biodiversidade (Myers et al. 2000). Atualmente restam de 11,4 a $16 \%$ da sua cobertura original (Ribeiro et al. 2009), sendo a ação antrópica a principal causa de sua redução (Morellato \& Haddad 2000). Poucos inventários abordaram Ericaceae para a Floresta Atlântica até então (e.g., Romão \& Souza 2003; Silva \& Cervi 2006; Marinero et al. 2007; Kinoshita \& Romão 2012; Mezabarba et al. 2013; Dutra et al. 2015; Cabral et al. 2016a, 2016b), devendo ser ressaltada a existência de apenas dois trabalhos taxonômicos para a família no estado do Espírito Santo (Romão \& Souza 2003; Coelho et al. 2010).

O presente estudo visa contribuir com o projeto "Flora do Estado do Espírito Santo", apresentando a riqueza de Ericaceae na área, com dados sobre habitats de ocorrência, descrições, ilustrações e chaves de identificação, além de comentários de distribuição geográfica, ecológicos e taxonômicos.

\section{Material e Métodos}

Os estudos foram conduzidos com base nas coleções dos herbários CESJ, CVRD, ESA, G, GFJP, HAS, HB, HUEFS, HUEMG, K, L, MBM, MBML, RB, RBR, S, SPF, UB, UEC e VIES [acrônimos segundo Thiers (continuously updated)]. O material examinado está listado em ordem alfabética de municípios e localidades específicas. No caso de haver mais de um material nestas condições a citação é cronológica. $\mathrm{Na}$ ausência de número de coleta, foi adotado como complemento o acrônimo do herbário acompanhado pelo respectivo número de registro.

Para a identificação e descrição dos espécimes foram utilizados Kinoshita-Gouvêa (1980), Kinoshita (1995), Judd (1995), Romão \& Souza (2003), Romão et al. (2004), Silva \& Cervi (2006), Kinoshita \& Romão (2010, 2011, 2012), Romão (2011), Mezabarba et al. (2013), Romão \& Souza (2014) e Cabral et al. (2016a, 2016b). A terminologia morfológica utilizada nas descrições das espécies foi baseada em Radford (1974), Harris \& Harris (2003) e Gonçalves \& Lorenzi (2007). Os dados sobre distribuição geográfica e fenologia foram obtidos em literatura e etiquetas das exsicatas, e os mapas para a distribuição das espécies foram elaborados utilizando DIVA-GIS 7.5 (Hijmans et al. 2014). Os dados referentes às fisionomias de ocorrência das espécies no Espírito Santo estão de acordo com Garbin et al. (2017).

\section{Resultados e Discussão}

No estado do Espírito Santo são encontrados os gêneros Agarista D. Don ex G. Don (Fig. 1a-e), Gaultheria L. (Fig. 1f-h) e Gaylussacia Kunth (Fig. 1i-o) representando um total de 11 espécies, que corrobora com estudos de Dutra et al. (2015): A. oleifolia (Cham.) G.Don var. oleifolia, Agarista oleifolia var. glabra (Meisn.) Judd, A. revoluta (Spreng.) J.D. Hooker ex Nied. var. revoluta, Gaultheria eriophylla (Pers.) Sleumer ex Burtt var. eriophylla, Gaultheria serrata var. organensis (Meisn.) Luteyn, Gaultheria serrata (Vell.) Sleumer ex Kin.-Gouv. var. serrata, Gaylussacia brasiliensis (Spreng.) Meisn. var. brasiliensis, Gaylussacia brasiliensis var. nervosa Meisn., Gaylussacia caparoensis Sleum., Gaylussacia densa Cham. var. densa, Gaylussacia fasciculata Gardn., Gaylussacia pallida Cham., Gaylussacia pulchra Pohl e Gaylussacia rugosa Cham. \& Schltdl.

Dessas espécies, cinco são endêmicas da Floresta Atlântica, sendo elas $A$. revoluta, Gaultheria eriophylla var. eriophylla, Gaultheria serrata, Gaylussacia fasciculata e Gaylussacia caparoensis (Romão 2009; BFG 2015), esta última ameaçada e incluída na categoria "Em Perigo" (EN) apenas por Martinelli et al. (2013). Os Campos de Altitude do Espírito Santo destacam-se por abrigar grande parte dos táxons de Ericaceae, sendo também de ocorrência restrita a este tipo de fitofisionomia no estado.

Gaylussacia brasiliensis é a espécie mais amplamente distribuída, encontrada em todas as regiões brasileiras, em um total de 14 estados (Romão 2011; BFG 2015). Esta espécie foi destacada por Romão (2011) pela sua ocorrência em vários habitats, desde a zona costeira até as cadeias montanhosas da região Centro-Oeste, apresentando grande variação morfológica. Por outro lado, G. caparoensis e G. pallida apresentam distribuição mais restrita quando comparada com às demais espécies no estado, ocorrendo apenas no Espírito Santo e Minas Gerais, sendo a primeira endêmica da Serra do Caparaó.

Comparado com outros inventários para a família no Brasil, nota-se um maior compartilhamento de espécies com regiões incluídas no domínio da Floresta Atlântica: flora 


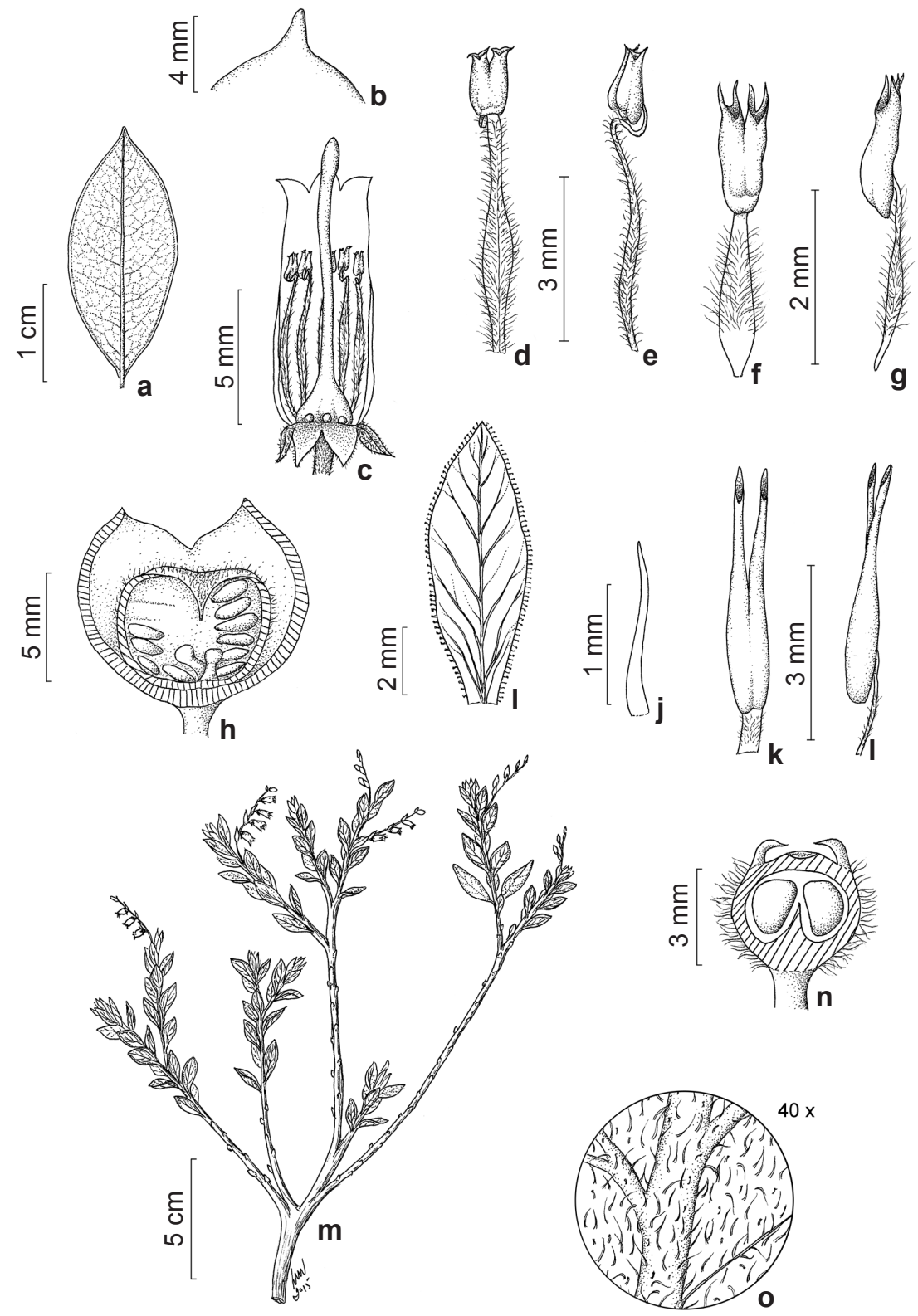

Figura 1 - a-c. Agarista revoluta - a. face abaxial da folha; b. detalhe da glândula apical da folha; c. corte longitudinal da flor. d,e. Agarista oleifolia var. oleifolia - d. vista frontal do estame; e. vista lateral do estame. f,g. Gaultheria eriophylla - f. vista frontal do estame; g. vista lateral do estame. h. Gaultheria serrata var. serrata-corte longitudinal do fruto. i,j. Gaylussacia brasiliensis var. brasiliensis - i. bráctea; j. bractéola. k,l. Gaylussacia caparoensis - k. vista frontal do estame; 1. vista lateral do estame. m,n. Gaylussacia pallida - m. hábito; n.: corte longitudinal do fruto. o. Gaylussacia pulchra - indumento da face abaxial da folha. (a,b. CESJ 20463; c. CESJ 20463; d,e. CESJ 24004; f,g. CESJ 23236; h. G.O. Romão 2730; i,j. CESJ 19560; k,1. CESJ 22602; m. L. Krieger FPNC 549; n. CESJ 22373 ; o. CESJ 31931).

Figure 1 - a-c. Agarista revoluta - a. abaxial side of the leaf; b. detail of the apical gland at the leaf apex; c. longitudinal section of the flower. d,e. Agarista oleifolia var. oleifolia - d. frontal view of the stamen; e. lateral view of the stamen. f,g. Gaultheria eriophylla - f. frontal view of the stamen; g. lateral view of the stamen. h.: Gaultheria serrata var. serrata - longitudinal section of the fruit. i,j. Gaylussacia brasiliensis var. brasiliensis - i. bract; j. bracteole. k,l. Gaylussacia caparoensis - k. frontal view of the stamen; 1 . lateral view of the stamen. m,n. Gaylussacia pallida - m. habit; n. longitudinal section of the fruit. o. Gaylussacia pulchra - indument of the abaxial side of the leaf. (a,b. CESJ 20463; c. CESJ 20463; d,e. CESJ 24004; f,g. CESJ 23236; h. G.O. Romão 2730; i,j. CESJ 19560; k,1. CESJ 22602; m. L. Krieger FPNC 549; n. CESJ 22373; o. CESJ 31931). 
do estado de São Paulo e do Parque Nacional do Itatiaia-RJ, com cinco espécies compartilhadas (Kinoshita \& Romão 2012; Mezabarba et al. 2013); flora do estado do Paraná, de Serra Negra-MG e do Parque Estadual da Serra do Papagaio-MG, com um total de três espécies compartilhadas (Silva \& Cervi 2006; Cabral et al. 2016a, 2016b).

\section{Tratamento taxonômico}

\section{Ericaceae Juss.}

Subarbusto a árvore, liana, epífita ou erva aclorofilada e micotrófica; tricomas unicelulares ou multicelulares, tectores, glandulares, dendríticos ou lepidotos; geralmente com glândulas diminutas. Folhas simples, alternas a opostas ou verticiladas, geralmente coriáceas, decíduas ou não; gemas peruladas; estípulas ausentes. Inflorescência em corimbo, fascículo, panícula, racemo ou flores solitárias; pedúnculo comumente bracteado na base; bráctea floral e bractéolas raramente ausentes. Flores bissexuadas, raramente unissexuadas, simetria radial ou ligeiramente bilateral; cálice (3-)5(-7)-lobado; pétalas (3-)4-5(-7), conatas ou raramente livres, corola urceolada, cilíndrica, campanulada ou infundibuliforme; androceu diplostêmone, raramente isostêmone, estames apendiculados ou não, geralmente epipétalos, filetes livres ou unidos, anteras dorsifixas ou basifixas, com 2 poros ou fendas apicais; disco nectarífero intraestaminal comumente presente; gineceu gamocarpelar, ovário súpero ou ínfero, 2-5(-pseudo 10)-locular, óvulos 1-numerosos por lóculo. Fruto do tipo baga, drupóide (nuculânio) ou cápsula; sementes de tamanho reduzido.

\section{Chave de identificação dos gêneros de Ericaceae no estado do Espírito Santo}

1. Ovário ínfero, pseudo 10-locular, lóculos uniovulados; fruto tipo nuculânio 3. Gaylussacia

1'. Ovário súpero, 4-5-locular, lóculos multiovulados; fruto tipo cápsula.

2. Cálice não carnoso, não acrescente à cápsula; filetes geniculados, anteras com tecas truncadas no ápice 1. Agarista

2'. Cálice carnoso acrescente à cápsula; filetes retos, antera com tecas biaristadas no ápice

2. Gaultheria

1. Agarista D. Don ex G. Don, Gen. hist. 3: 837. 1834.

Leucothoe D. Don subgen. Agarista (D. Don ex G. Don) Drude in Engler \& Prantl, Nat. Pflanzenfam. 1(4): 42.1889.

Subarbusto a árvore; tricomas tectores ou glandulares, em geral glândulas foveoladas enegrecidas associadas às nervuras secundárias foliares. Folhas alternas ou subopostas, em geral imbricadas, persistentes; pecíolo robusto ou delgado, às vezes flexível; lâminas subcoriáceas a rigidamente coriáceas, raramente cartáceas, planas ou conduplicadas, margem geralmente revoluta, frequentemente com glândulas apicais. Inflorescência em panícula ou racemo, bracteada ou não na base do eixo da inflorescência; bráctea 1 , pouco vistosa, bractéolas 2. Flores actinomorfas, 5-meras, bissexuadas, diplostêmones, pendentes ou raramente eretas; cálice conato na base, não carnoso, não acrescente ao fruto; corola gamopétala, urceolada a cilíndrica, alva, creme, amarelo-esverdeada ou vermelha, lobos retos ou recurvados; estames 10, iguais entre si, eretos, filetes geniculados, achatados, anteras bífidas, dorsifixas na metade inferior, deiscência poricida, teca truncada, desprovida de apêndice; ovário súpero, 5-locular, lóculos multiovulados. Cápsula loculicida, septos lenhosos, costada; sementes fusiformes.

Sleumer (1959) reconheceu as espécies de Agarista D. Don ex G. Don na circunscrição do gênero Leucothoe D. Don. Contudo, Judd (1984) restabeleceu o gênero Agarista com base em estudos cladísticos, sendo caracterizado por apresentar porte geralmente arbustivo, inflorescências racemosas, corolas urceoladas a cilíndricas, filetes geniculados e frutos capsularloculicidas.

O gênero é constituído por 31 espécies, ocorrendo predominantemente nas Américas. No Brasil, estão relacionadas 21 espécies ocorrendo principalmente nos campos rupestres da Cadeia do Espinhaço até os campos de altitude nas regiões Sul e Sudeste (Judd 1995; BFG 2015). No Espírito Santo, são encontradas duas espécies (Fig. 1a-e) distribuídas nas restingas e nos campos de altitude da Serra do Caparaó. 
Chave de identificação das espécies de Agarista no Espírito Santo

1. Folhas com margem plana, limbo lanceolado a estreitamente elíptico; ramos glabros, às vezes pubescentes a tomentelos nos râmulos. 1.1. Agarista oleifolia

1'. Folhas com margem fortemente revoluta, limbo elíptico a ovalado; ramos densamente pubescentes... 1.2. Agarista revoluta

1.1. Agarista oleifolia (Cham.) G. Don, Gen. Hist. 3: 838. 1834. Andromeda oleifolia Cham., Linnaea 8: 504.1833.

Fig. 2

Arbusto a arvoreta, raramente subarbusto, 0,4-3 m alt.; tricomas tectores nos ramos, folhas, flores e frutos, alvos ou ferrugíneos, tricomas glandulares ausentes, desprovida de glândulas diminutas; ramos glabros, às vezes pubescentes a tomentelos nos râmulos. Folhas cartáceas, limbo lanceolado a estreitamente elíptico, 0,9-8,3 $\times$ $0,5-2,4 \mathrm{~cm}$, ápice agudo, mucronulado, glândula apical cônico-alongada, base arredondada a obtusa, margem plana, inteira, ambas as faces glabras ou esparsamente cano-pubescentes na nervura principal, raramente glândulas foveoladas conspícuas e enegrecidas associadas às nervuras secundárias na face abaxial. Racemo ou panícula, axilar ou terminal, raque $1,8-7,8 \mathrm{~cm}$ compr., glabra ou densamente ferrugíneo-tomentosa; brácteas setiformes, bractéolas filiformes a setiformes. Pedicelo 2-10 mm compr.; cálice 1-3 mm compr., tomentoso, mais densamente nos bordos dos lobos; corola 5-11 mm compr., branca ou amarelo-esverdeada, urceolada ou cilíndrica, glabra. Cápsula 3-7 mm diâm., castanha a esverdeada, subglobosa, costada, glabra a esparsamente pubescente na base.

Agarista oleifolia pode ser prontamente diferenciada de $A$. revoluta, a outra espécie do gênero que ocorre no Espírito Santo, pela presença de folhas com margem plana e limbo lanceolado a estreitamente elíptico, em contraste com as folhas com margem fortemente revoluta $\mathrm{e}$ limbo elíptico a ovalado em $A$. revoluta. Agarista oleifolia é bastante semelhante no aspecto geral a $A$. minensis, $A$. niederleinii var. acutifolia $\mathrm{e}$ A. uleana, que não ocorrem na área de estudo, como já observado por Romão \& Souza (2003). Diferem principalmente quanto à posição das sementes no fruto, além da distribuição geográfica. As espécies que apresentam cápsulas com placentação central são $A$. minensis, que ocorre na Região Sul brasileira, e A. oleifolia cuja ocorrência é mais ampla desde a Cadeia do Espinhaço adentrando pelo Brasil central até áreas de maiores altitudes na Floresta Atlântica, desde o Espírito Santo até São Paulo. Por outro lado, apresentam cápsulas com placentação subapical $A$. niederleinii var. acutifolia, que se distribui pelas áreas de maiores altitudes na Floresta Atlântica de São Paulo até o Rio Grande do Sul, e A. uleana a qual está restrita à costa na Floresta Atlântica do Rio de Janeiro.

Judd (1984) reconheceu duas variedades com base no indumento da raque da inflorescência e tamanho da corola. São encontradas no Espírito Santo as variedades Agarista oleifolia var. oleifolia e A. oleifolia var. glabra (Meisn.) Judd.

\section{Chave de identificação das variedades de Agarista oleifolia}

1. Raque da inflorescência densamente ferrugíneo-tomentosa ........1.1.1. Agarista oleifolia var. oleifolia

1'. Raque da inflorescência glabra 1.1.2. Agarista oleifolia var. glabra

1.1.1. Agarista oleifolia (Cham.) G. Don var. oleifolia.

Fig. 1d,e

Leucothoe oleifolia (Cham.) DC., Prodr. 7: 605. 1839. Leucothoe ambigua Meisn. in Mart. \& Eichler, Fl. bras. 7: 156. 1863.

Leucothoe stenophylla Loes., Flora 72: 77. 1889. Material selecionado: Marilândia, Pedra do Cruzeiro, 29.VI.2006, fl., L.F.S. Magnago et al. 1389 (ESA,
MBML). Santa Teresa, Papaçu, 23.IX.2006, fl., L. Kollmann et al. 9315 (ESA, MBML).

Material adicional examinado: BRASIL. MINAS GERAIS: Alto Caparaó, Parque Nacional do Caparaó, 22.VII.2006, f1., G.O. Romão \& A.P.T. Dantas 1485 (ESA). Agarista oleifolia var. oleifolia está distribuída ao longo da Cadeia do Espinhaço em Minas Gerais e Bahia e áreas de maiores altitudes 


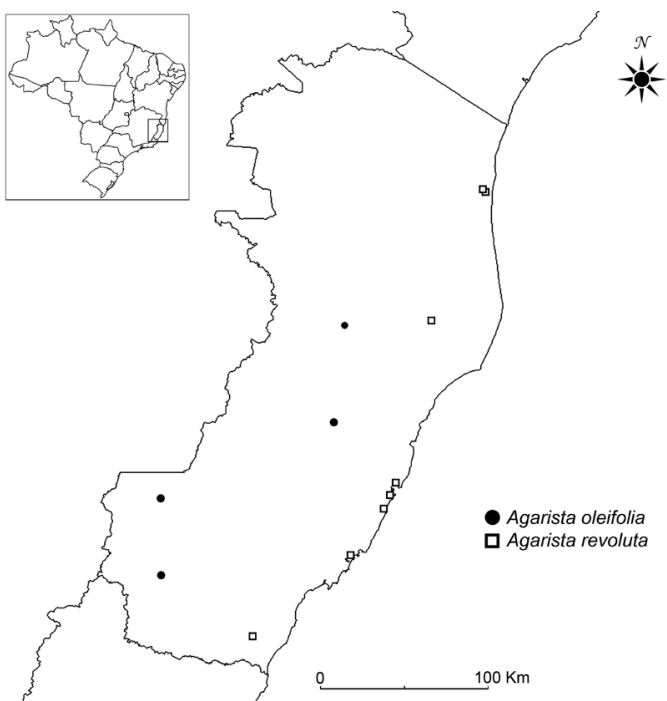

Figura 2 - Mapa de distribuição geográfica das espécies de Agarista no Espírito Santo, Brasil.

Figure 2 - Geographic distribution map of Agarista species in Espírito Santo state, Brazil.

da Floresta Atlântica no Espírito Santo até o Paraná, adentrando pelo Brasil central em Goiás e Mato Grosso. No Espírito Santo é encontrada em áreas de capões de mata ou matas ciliares adjacentes a campos de altitude, entre 1.800-2.400 m.

Ilustrações em Meisner (1863, sob Leucothoe oleifolia), Kinoshita-Gouvêa (1980, sob L. oleifolia), Judd (1984, 1995), Romão \& Souza (2003), Kinoshita \& Romão (2012), Mezabarba et al. (2013), Romão \& Souza (2014) e Cabral et al. $(2016 \mathrm{a}, \mathrm{b})$.

1.1.2. Agarista oleifolia var. glabra (Meisn.) Judd, J. Arnold Arbor. 65: 310. 1984.

Leucothoe ambigua var. glabra Meisn. in Mart., Fl. bras. 7: 156. 1863.

Leucothoe oleifolia var. glabra (Meisn.) Sleum., Bot. Jahrb. Syst. 78: 476. 1959.

Material selecionado: Alegre, Rio Braço Norte, 19.X.2000, fl., W. Forster \& G.O. Romão 792 (ESA).

Iúna, Parque Nacional do Caparaó, entre Arrozal e Rancho dos Cabritos, 18.II.2000, fl. e fr., V.C. Souza et al. 23393 (ESA, GFJP).

Material adicional examinado: BRASIL. MINAS GERAIS: Alto Caparaó, Parque Nacional do Caparaó, córrego José Pedro, 20.II.2000, fr., V.C. Souza et al. 23526 (ESA, GFJP, UEC). Espera Feliz, Parque Nacional do Caparaó, Macieiras, 19.X.1999, fl., W. Forster et al. 111 (ESA).

Agarista oleifolia var. glabra está distribuída ao longo da Cadeia do Espinhaço na Bahia e Minas
Gerais, adentrando pelo Brasil central e áreas de maiores altitudes na Floresta Atlântica no Espírito Santo, onde é encontrada em áreas de capões de mata ou matas ciliares adjacentes a campos de altitude, em torno de $1.800 \mathrm{~m}$.

Ilustrações em Judd (1984, 1995) e Romão et al. (2004).

1.2. Agarista revoluta (Spreng.) J.D. Hooker ex Nied., Bot. Jahrb. Syst. 11:236. 1889. Andromeda revoluta Spreng., Neue Entdeck. 2: 131. 1821.

Figs. 1a-c; 2

Leucothoe revoluta var. sellowii Meisn. in Mart., Fl. bras. 7: 160. 1863.

Nome vulgar: "alecrim-do-rego".

Arbusto a árvore 1-6 $\mathrm{m}$ alt.; tricomas tectores nos ramos, folhas, flores e frutos, alvos, tricomas glandulares ausentes, desprovida de glândulas diminutas; ramos densamente pubescentes. Folhas cartáceas, limbo elíptico a ovalado, 1,6-3,6 × 0,8-2,1 cm, ápice arredondado a obtuso, mucronulado, glândula apical cônico-alongada, base arredondada a obtusa ou subcordada, margem fortemente revoluta, inteira, face adaxial glabra a esparsamente pubescente na nervura principal, face abaxial mais densamente pubescente na nervura principal, glândulas foveoladas conspícuas e enegrecidas associadas às nervuras secundárias. Racemo axilar, raque $0,9-3,7 \mathrm{~cm}$ compr., densamente pubescente a tomentosa; brácteas e bractéolas setiformes. Pedicelo 5-7 mm compr.; cálice 1-2 mm compr., glabro ou raro densamente pubescente; corola 5-9 $\mathrm{mm}$ compr., branca ou creme, urceolada, glabra. Cápsula 5-8 mm diâm., castanha a negra, globosa, costada, pubescente a vilosa principalmente na base.

Material selecionado: Conceição da Barra, Lajinha, 5.VII.2007, fr., C. Farney et al. 4766 (RB, VIES). Guarapari, 29.IX.1980, fl., L. Krieger (CESJ 20463, ESA). Linhares, Reserva Natural da Vale, Estrada da Boleira, nativo da Gávea, 18.IV.2011, fr., J. Meirelles et al. 579 (CVRD, CTES, ESA, MBM, RB). Vila Velha, 26.VII.1982, fl. e fr., M. Sazima 14054 (UEC). Presidente Kennedy, Praia das Neves, 14.I.2010, fr., Maielo-Silva 87 (RB). São Mateus, bairro Quadrado, campus do CEUNES, 30.XI.2011, fr., A.O. Giaretta 1079 (VIES). Vila Velha, Reserva Estadual de Jacarenema, 15.VII.2004, fr., G. G.K. Lube \& O.J. Pereira 143 (VIES). Vitória: Reserva Ecológica do Camburi, 2.IX.1998, fl., A.M. Assis 577 (VIES).

Agarista revoluta está distribuída pelo domínio da Floresta Atlântica, ao longo da região costeira da Bahia até o Rio de Janeiro. No Espírito Santo é encontrada em restingas e em 
campos nativos na Reserva Natural da Vale. Essa espécie relaciona-se com Agarista duckei por apresentar folhas com limbo abaulado e margem fortemente revoluta, como já relatado por Judd (1995). Contudo, diferem principalmente quanto ao tamanho da inflorescência e ápice foliar, além da distribuição geográfica, visto que $A$. revoluta apresenta folhas com ápice arredondado a obtuso, raque da inflorescência maior $(0,9-6,5 \mathrm{~cm})$ e distribuída pela Floresta Atlântica, enquanto que $A$. duckei possui folhas com ápice acuminado, raque da inflorescência menor (0,5-1,5 cm compr.) e distribuída no domínio Amazônico.

Judd (1984) reconheceu duas variedades para essa espécie, com base no indumento da face abaxial das folhas e da corola. No Espírito Santo é encontrada apenas Agarista revoluta var. revoluta, que se caracteriza por apresentar folhas com face abaxial densamente pubescente na nervura principal e corola glabra.

Ilustrações em Judd (1984, 1995) e Coelho et al. (2010).

2. Gaultheria L., Sp. pl. 1: 395. 1753.

Subarbusto a árvore; tricomas tectores ou glandulares. Folhas alternas, comumente não imbricadas, persistentes; pecíolo robusto, às vezes canaliculado; lâminas geralmente coriáceas, planas, margem às vezes revoluta, frequentemente com glândulas apicais. Inflorescência em panícula, racemo ou fascículo, raramente flores solitárias, bracteada ou não na base do eixo da inflorescência; bráctea 1, foliácea, bractéolas 2-12. Flores actinomorfas, 4-5-meras, bissexuadas, diplostêmones, frequentemente pendentes; cálice conato na base, articulado com o pedicelo, carnoso acrescente ao fruto; corola gamopétala, urceolada a cilíndrica, raro campanulada, alva ou vermelha, lobos frequentemente recurvados; estames 8-10, geralmente iguais entre si, eretos, filetes retos, achatado-subulados, anteras bífidas, dorsifixas, poricida ou deiscência por pequena fenda, teca apendiculada, biaristada; ovário súpero, 4-5-locular, lóculos multiovulados. Cápsula loculicida, geralmente envolvida pelo cálice carnoso acrescente; sementes ovóides ou anguladas.

A delimitação de algumas espécies de Gaultheria é ainda muito discutida, uma vez que muitas delas formam híbridos naturais e conferem dificuldades nos tratamentos taxonômicos baseados em morfologia (Luteyn 1995).

O gênero é constituído por 115 espécies de distribuição cosmopolita. No Brasil, estão relacionadas oito espécies e um híbrido, sendo que duas delas (Fig. 1f-h ) ocorrem no estado do Espírito Santo, distribuídos nos campos de altitude da Serra do Caparaó (Luteyn 1995; BFG 2015).

\section{Chave de identificação das espécies de Gaultheria no Espírito Santo}

1. Folhas com face abaxial densamente tomentoso-lanosa em todo o limbo, tricomas ferrugíneos 2.1. Gaultheria eriophylla

1'. Folhas com face abaxial glabra a tomentosa ou híspido-glandular, mais densamente na nervura principal, tricomas alvos 2.2. Gaultheria serrata

2.1. Gaultheria eriophylla (Pers.) Sleum. ex Burtt, Bot. Mag. 170: t.254. 1955. Andromeda eriophylla Pers., Syn. pl. 1: 482. 1805.

Gaultheria ferruginea Cham. \& Schltdl., Linnaea 1: 524.1826.

Figs. 1f,g; 3

Subarbusto a arbusto $0,2-3 \mathrm{~m}$ alt.; tricomas tectores nos ramos, folhas, flores e frutos, ferrugíneos, tricomas glandulares ausentes, desprovida de glândulas diminutas; ramos densamente tomentosos a lanosos, gemas foliares protegidas por catáfilos vistosos. Folhas coriáceas, limbo largamente elíptico a suborbicular ou ovalado, 2,4-10,2 × 0,9-5,7 cm, ápice obtuso a agudo, apiculado, glândula apical espessoalongada, base cordada ou arredondada, margem revoluta, inteira, face adaxial esparsamente tomentosa, mais densamente na nervura principal, face abaxial densamente tomentoso-lanosa em todo o limbo. Racemo terminal, raque 3,1-7,8 cm compr., densamente tomentoso-lanosa; brácteas obovadas a rômbicas, bractéolas lanceoladas a setiformes. Pedicelo 3-9 mm compr.; cálice 1-4 mm compr., densamente tomentoso-lanoso; corola 3-5 mm compr., vermelha a rosada, raro arrexeada, urceolada, densamente tomentoso-lanosa. Cápsula 3-4 mm diâm., dourada a negra, globosa, costada, esparsamente cano-pubescente. 
Material selecionado: Alegre, Caveira da Anta, 12.X.2007, fl. e fr., D.R. Couto et al. 369 (ESA, MBML). Alfredo Chaves, São Bento de Urânia, 18.X.2000, fl., G. Hatschbach et al. 71391 (MBM). Castelo, Parque Estadual Forno Grande, 30.X.2004, fl., L. Kollmann 7158 (MBML). Domingos Martins, Parque Nacional da Pedra Azul, cume da Pedra das Flores, 11.VII.2006, fl. e fr., A.P. Fontana et al. 2214 (ESA, MBML, RB). Iúna, Serra do Valentim, 17.XI.2011, fl., J.P.F. Zorzanelli et al. 156 (VIES). São Roque do Canaã, Alto Misterioso, 30.IX.2006, fl., L. Kollmann et al. 9352 (ESA, MBML). Vargem Alta, VI.1982, fl., B. Weinberg 400 (ESA, MBML).

Material adicional examinado: BRASIL. MINAS GERAIS: Alto Caparaó, Parque Nacional do Caparaó, Trilha Tronqueira-Pico da Bandeira, 11.IV.2010, fl. e fr., G.O. Romão et al. 2710 (ESA, RB, UEC). Espera Feliz, Parque Nacional do Caparaó, Macieira, 28.V.1999, fl., W. Forster \& L. Leoni 72 (ESA).

Gaultheria eriophylla é facilmente distinta das demais espécies do gênero por apresentar, na face abaxial das folhas e na raque da inflorescência, um indumento densamente tomentoso-lanoso com tricomas ferrugíneos. Essa espécie está distribuída nas áreas de maiores altitudes do domínio da Floresta Atlântica, desde a região do Alto Misterioso no Espírito Santo até a Serra da Mantiqueira em São Paulo. No Espírito Santo é encontrada em áreas de campos de altitude em meio aos afloramentos rochosos ou proximidades de matas nebulares, entre altitudes de 1.000-2.890 m.

Luteyn (1995) reconheceu duas variedades com base no formato e ápice das folhas, no indumento da planta e distribuição geográfica. Foi encontrada no Espírito Santo apenas G. eriophylla var. eriophylla, que se caracteriza pelas folhas com limbo elíptico ou ovalado, com ápice obtuso a agudo, indumento tomentoso-ferrugíneo e de ocorrência no sudeste brasileiro, enquanto que G. eriophylla var. mucronata (Remy) Luteyn está restrita nos Andes ao norte da Bolívia e sul do Peru.

Ilustrações em Meisner (1863, sob $G$. ferruginea), Kinoshita-Gouvêa (1980), Kinoshita \& Romão (2012), Mezabarba et al. (2013) e Cabral et al. (2016a,b).

2.2. Gaultheria serrata (Vell.) Sleum. ex Kin.Gouv., Brittonia 41: 16. 1989. Andromeda serrata Vell., Fl. flumin. 174. 1825.

Fig. 3

Subarbusto a arbusto $0,2-2 \mathrm{~m}$ alt.; tricomas tectores nos ramos, folhas e flores, alvos, tricomas glandulares presentes ou não, nos ramos, folhas e raque da inflorescência, ferrugíneos, raramente glândulas clavadas diminutas nos ramos e folhas;

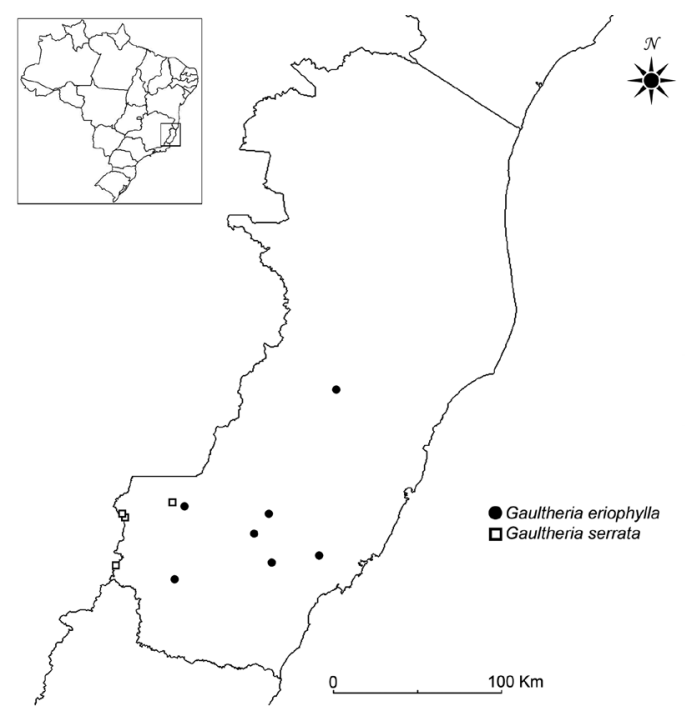

Figura 3 - Mapa de distribuição geográfica das espécies de Gaultheria no Espírito Santo, Brasil.

Figure 3 - Geographic distribution map of Gaultheria species in Espírito Santo state, Brazil.

ramos avermelhados, glabros ou esparsamente tomentosos a setosos e híspido-glandulares. Folhas coriáceas, limbo elíptico ou ovalado, $1,1-7,1 \times 0,6-4,2 \mathrm{~cm}$, ápice obtuso a agudo, mucronulado, glândula apical espesso-alongada, base obtusa, arredondada ou subcordada, margem ligeiramente revoluta, serreada, ambas as faces lisas ou escabras, glabras a pubescentes ou tomentosas a híspido-glandulares, mais densamente na nervura principal da face abaxial, geralmente com cicatrizes dos tricomas glandulares caducos. Racemo axilar ou terminal, raque $1,2-7,2 \mathrm{~cm}$ compr., pubescente a tomentosa e densamente híspido-glandular; brácteas obovadas a rômbicas, bractéolas lanceoladas a elípticas. Pedicelo 4-9 mm compr.; cálice 2-5 $\mathrm{mm}$ compr., pubescente a tomentosa e às vezes híspido-glandular; corola 5-8 $\mathrm{mm}$ compr., vermelha a rosada, urceolada, pubescente a tomentosa. Cápsula 3-4 mm diâm., castanha a vinácea, globosa, lisa, lustrosa, glabra a pubescente.

Gaultheria serrata é facilmente distinta da outra espécie do gênero no Espírito Santo por apresentar folhas com margem serreada e indumento frequentemente ferrugíneo e escabro.

Kinoshita-Gouvêa (1980) considerou Gaultheria serrata e G. organensis distintamente, além de um híbrido G. x caparoensis, separados 
pelo indumento dos ramos e das folhas. No entanto, Luteyn (1995) reconheceu os táxons citados como uma única espécie polimórfica, separando-a em duas variedades com base principalmente no indumento dos ramos. São encontradas no Espírito Santo as variedades $G$. serrata (Vell.) Sleum. ex Kin.-Gouv. var. serrata e G. serrata var. organensis (Meisn.) Luteyn.

\section{Chave de identificação das variedades de Gaultheria serrata}

1. Ramos glabros, face foliar adaxial lisa, glabra a pubescente ..... 2.2.1. Gaultheria serrata var. serrata

1'. Ramos tomentosos ou híspido-setosos, face foliar adaxial escabra, tomentosa a híspida 2.2.2. Gaultheria serrata var. organensis

2.2.1. Gaultheria serrata (Vell.) Sleum. ex Kin.Gouv. var. serrata.

Fig. $1 \mathrm{~h}$

Gaultheria elliptica Cham., Linnaea 8: 502. 1833.

Material selecionado: Alegre, Serra do Caparaó, 2.III.1959, fl., H.S. Irwin 2764 (NY). Iúna, Parque Nacional do Caparaó, Arrozal, 18.II.2000, fl. e fr., V.C. Souza et al. 23330 e 23412 (ESA, GFJP).

Material adicional examinado: BRASIL. MINAS GERAIS: Alto Caparaó, Parque Nacional do Caparaó, Trilha Tronqueira-Pico da Bandeira, 11.IV.2010, fl. e fr., G.O. Romão et al. 2730 (ESA, HUEFS, RB, UB, UEC).

Gaultheria serrata var. serrata está distribuída nas áreas de maiores altitudes no domínio da Floresta Atlântica, entre a Serra do Caparaó em Minas Gerais e Espírito Santo até o Paraná. No Espírito Santo é encontrada em campos de altitude na Serra do Caparaó, entre 1.970-2.890 m.

Ilustrações em Kinoshita-Gouvêa (1980), Mezabarba et al. (2013) e Cabral et al. (2016b).

2.2.2. Gaultheria serrata var. organensis (Meisn.) Luteyn, Fl. Neotrop. Monogr. 66: 458. 1995. Gaultheria organensis Meisn. in Mart. \& Eichler, Fl. bras. 7: 153. 1863.

Gaultheria x caparoensis Brade ex Sleum., Bot. Jahrb. Syst. 75: 448. 1952.

Material selecionado: Dores do Rio Preto, Parque Nacional do Caparaó, trilha para Pedra Duas Irmãs, 22.III.2012, fl., J. Kuntz et al. 623 e 626 (ESA, HUEMG). Material adicional examinado: BRASIL. MINAS GERAIS: Alto Caparaó, Parque Nacional do Caparaó, trilha Tronqueira-Terreirão, 22.VII.2006, fl., G.O. Romão \& A.P.T. Dantas 1483 (ESA).

Gaultheria serrata var. organensis está distribuída nas áreas de maiores altitudes no domínio da Floresta Atlântica, desde a Serra do Caparaó entre Minas Gerais e Espírito Santo até Santa Catarina. No Espírito Santo é encontrada em campos de altitude na Serra do Caparaó, entre 1.970-2.890 m.

Ilustrações em Marques (1975, sob G. organensis), Kinoshita-Gouvêa (1980), Silva \& Cervi (2006) e Kinoshita \& Romão (2012).
3. Gaylussacia Kunth, Nov. Gen. Sp. Pl. 3: 275. 1818.

Subarbusto a arbusto, raramente arvoreta ou árvore; tricomas tectores ou glandulares, glândulas diminutas clavadas, capitadas, punctadas ou discóides. Folhas alternas ou subopostas, em geral imbricadas, raramente decíduas; pecíolo robusto; lâminas cartáceas a rigidamente coriáceas, planas, margem inteira a crenulada, plana a fortemente revoluta, com glândulas apicais e marginais. Inflorescência em panícula ou racemo, bracteada na base do eixo da inflorescência; bráctea 1, vistosa, bractéolas 2. Flores actinomorfas, 5-meras, bissexuadas, diplostêmones, frequentemente pendentes; cálice conato na base, não carnoso; corola gamopétala, urceolada, tubulosa, cilíndrica ou campanulada, alva, rosada ou vermelha, lobos retos ou recurvados; estames 10 , iguais entre si, eretos, filetes retos, achatados, anteras bífidas, dorsifixas, deiscência poricida ou por pequena fenda apical introrsa, teca longo-tubulosa; disco nectarífero dilatado; ovário ínfero, pseudo 10-locular, 1 óvulo por lóculo. Nuculânio com 10 pirênios; sementes lenticulares, umbílicopunctiformes.

Gaylussacia é um gênero constituído por 54 espécies com distribuíção subtropical atlântica da América do Norte e na América do Sul tropical e subtropical, estando completamente ausente na América Central (Sleumer 1967; Kinoshita 1995; Romão 2011). No Brasil, estão relacionadas 43 espécies ocorrendo em restingas, campinaranas, carrascos e principalmente campos rupestres da Cadeia do Espinhaço até os campos de altitude nas regiões Sul e Sudeste, adentrando pelos afloramentos rochosos do Brasil central (Kinoshita \& Romão 2010; Romão 2011). No Espírito Santo, são encontradas sete espécies distribuídas nas restingas e nos campos de altitude, principalmente na região da Serra do Caparaó. 


\section{Chave de identificação das espécies de Gaylussacia no Espírito Santo}

1. Ramos, folhas e flores com tricomas glandulares e tectores.

2. Folhas com face adaxial bulada, corola vermelha a rosada. 3.6. Gaylussacia pulchra

2'. Folhas com face adaxial não bulada, corola branca 3.7. Gaylussacia rugosa

1'. Ramos, folhas e flores apenas com tricomas tectores.

3. Catáfilos persistentes nos ramos, corola tubuloso-campanulada a largamente campanulada ou cilíndrica.

4. Ramos pubescentes a tomentelos, margem das folhas serrilhada da base até o ápice.... 3.2. Gaylussacia caparoensis

4'. Ramos densamente setosos a vilosos, margem das folhas subcrenulada próximo do ápice

3.5. Gaylussacia pallida

3'. Catáfilos precocemente decíduos nos ramos, corola urceolada ou tubuloso-urceolada.

5. Brácteas lanceoladas a obtruladas, corola vermelha a rosada, 5-9 mm de comprimento 3.1. Gaylussacia brasiliensis

5'. Brácteas obovadas ou elípticas a rômbicas, corola branca, 4-6 $\mathrm{mm}$ de comprimento.

6. Folhas subcoriáceas, elípticas a obovadas, 0,5-1,7 × 0,3-0,9 cm 3.3. Gaylussacia densa

6'. Folhas cartáceas, obovadas, 1,6-7 × 0,7-4,2 cm .......3.4. Gaylussacia fasciculata

3.1. Gaylussacia brasiliensis (Spreng.) Meisn., $F l$. bras. 7: 129. 1863. Vaccinium brasiliense Spreng., Nov. Prov.: 42. 1819.

Fig. 4

Arbusto 0,3-1,5(-3) m alt.; tricomas tectores nos ramos, folhas e flores, alvos, tricomas glandulares ausentes, glândulas clavadas ou capitadas diminutas nas folhas, raque das inflorescências e flores, rubro-nigrescentes; ramos glabros a esparsamente pubescentes, catáfilos precocemente decíduos. Folhas cartáceas a subcoriáceas ou coriáceas, limbo elíptico ou ovalado a obovado, raro suborbicular, 1,3-4,9 $\times$ $0,8-2,4(-3,1) \mathrm{cm}$, ápice arredondado a agudo, às vezes emarginado, mucronulado, glândula apical espesso-calosa, base aguda a arredondada, margem plana a ligeiramente revoluta, serrilhada próximo do ápice, ambas as faces glabras ou esparsamente pubescentes na base do limbo e da nervura principal, glândulas esparsamente dispostas em todo o limbo na face abaxial, nervação proeminente ou elevadoproeminente na face abaxial. Racemo axilar, raque 1,8-5,2 cm compr., glabra a esparsamente pubescente; brácteas lanceoladas a obtruladas, bractéolas filiformes, ambas comumente providas de glândulas apicais. Pedicelo 4-8 mm compr.; cálice 1-3 mm compr., glabro ou ciliado; hipanto glabro, glândulas esparsas; corola 5-9 mm compr., vermelha a rosada, urceolada, glabra. Nuculânio 3-5 mm diâm., negro a avermelhado, depressoovoide ou subgloboso, costado, glabro.

Gaylussacia brasiliensis é a espécie mais amplamente distribuída no Brasil, ocorrendo desde a planície costeira até as cadeias montanhosas da Região Centro-Oeste, além de ser a espécie mais variável morfologicamente dentro do gênero (Kinoshita \& Romão 2011; Romão 2011). No aspecto geral da planta, essa espécie assemelha-se a outras quatro espécies do gênero, das quais apenas G. pulchra Pohl ocorre no Espírito Santo, sendo as demais: G. amoena Cham., G. martii Meisn. e G. retusa Mart. ex Meisn. Em geral, G. brasiliensis

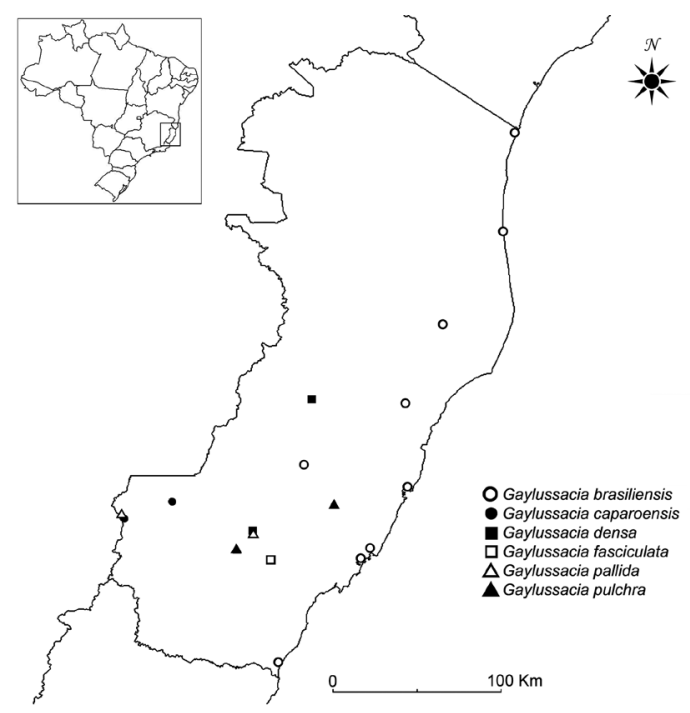

Figura 4 - Mapa de distribuição geográfica das espécies de Gaylussacia no Espírito Santo, Brasil.

Figure 4-Geographic distribution map of Gaylussacia species in Espírito Santo state, Brazil. 
é caracterizada por apresentar corola urceolada e frequentemente vermelho-coccínea, brácteas e bractéolas comumente com glândulas apicais e ausência de tricomas glandulares, e difere de $G$. amoena que possui corola campanulada, branca ou rosada nos ângulos, de G. martii que possui corola cilíndrica a campanulada, branca, brácteas e bractéolas desprovidas de glândula apical, de $G$. retusa que apresenta tricomas glandulares nas flores, e de G. pulchra que possui face adaxial das folhas bulada e tricomas glandulares nos ramos, folhas e flores.
Meisner (1863) e Sleumer (1967) reconheceram ao todo 12 variedades com base na densidade do indumento. Marques (1975) notou dificuldades na separação das variedades, enquanto Kinoshita-Gouvêa (1980) e Romão (2011) reconhecem somente duas variedades, baseados na consistência e nervação das folhas. São encontradas no Espírito Santo as duas variedades reconhecidas por Kinoshita-Gouvêa (1980) e Romão (2011): Gaylussacia brasiliensis (Spreng.) Meisn. var. brasiliensis e G. brasiliensis var. nervosa Meisn.

\section{Chave de identificação das variedades de Gaylussacia brasiliensis}

1. Folhas coriáceas, nervação distintamente elevada e proeminente na face abaxial 3.1.2. Gaylussacia brasiliensis var. nervosa

1'. Folhas cartáceas a subcoriáceas, nervação ligeiramente proeminente na face abaxial, nunca distintamente elevada 3.1.1. Gaylussacia brasiliensis var. brasiliensis

\subsubsection{Gaylussacia brasiliensis (Spreng.) Meisn. var. brasiliensis. \\ Nome vulgar: "balaio", "camarinha". Fig. $i, j$}

Material selecionado: Alfredo Chaves, São Bento de Urânia, 18.X.2000, fl., G. Hatschbach et al. 71397 (MBM). Aracruz, Brejo Grande, 12.I.2003, fl., O.J. Pereira et al. 2803 (VIES). Conceição da Barra, estrada para litoral de Riacho Doce, 28.VIII.2012, fl. e fr., T.B. Flores \& G.O. Romão 1237 (CVRD, ESA, MBML, RB, VIES, UEC). Guarapari, 30.IV.1981, fl., L. Krieger (CESJ 19560, ESA). Linhares, Reserva Natural da Vale, 18.IV.2011, fl., J. Meirelles et al. 576 (CVRD, ESA). Presidente Kennedy, estrada para praias das Neves Km 38 da BR 101, 16.VII.2006, fl. e fr., J.P. Souza et al. 6044 (ESA). Santa Maria de Jetibá, Garrafão, 6.VI.2009, fl. e fr., T.S. Lorencini et al. 290 (VIES). São Mateus, bairro Litorâneo, 1.VIII.2007, fl. e fr., R.F.A. Martins et al. 37 (VIES). Setiba, Parque Estadual Paulo César Vinha, 17.VIII.2009, fl. e fr., S.S. Dutra et al. 128 (VIES). Sooretama/Linhares, $6 \mathrm{~km}$ ao sul de Sooretama, 15.XII.1962, fr., J. Mattos (HAS 81150). Vitória, Camburi, 5.VIII.1988, fl., O.J. Pereira et al. 1722 (VIES).

Gaylussacia brasiliensis var. brasiliensis é amplamente distribuída pelo Brasil, ocorrendo ao longo da costa entre os estados da Paraíba até o Rio Grande do Sul, adentrando pela Cadeia do Espinhaço em Minas Gerais e Bahia, além do planalto central no Distrito Federal até o nordeste do Mato Grosso do Sul. No Espírito Santo é encontrada em áreas de restinga, sendo bastante abundante em "área aberta de Ericaceae" nas restingas de Camburi (Pereira \& Assis 2000), bordas de matas entre os municípios de Conceição da Barra e Presidente Kennedy, além de Nativos e Mussunungas na Reserva Natural da Vale do Rio Doce, entre altitudes de 6-900 m.

Ilustrações em Stevens (1971), Marques (1975), Silva \& Cervi (2006), Kinoshita-Gouvêa (1980), Amaral et al. (2008), Souza \& Lorenzi (2008), Coelho et al. (2010), Romão (2011), Kinoshita \& Romão (2012) e Mezabarba et al. (2013).

\subsubsection{Gaylussacia brasiliensis var. nervosa} Meisn., Fl. bras. 7: 130. 1863.

Material examinado: Rio Doce: Serra Pintaba, II.1917, fl., Lutzelburg 7156 (M).

Gaylussacia brasiliensis var. nervosa ocorre predominantemente no domínio do Cerrado em Goiás e ao longo da Cadeia do Espinhaço em Minas Gerais e Bahia, adentrando esporadicamente no Espírito Santo. É encontrada, no Espírito Santo, em áreas campestres na região de Rio Doce, em altitudes em torno de $1.000 \mathrm{~m}$.

3.2. Gaylussacia caparoensis Sleum., Bot. Jahrb. Syst. 86: 362. 1967.

Figs. $1 \mathrm{k}, 1 ; 4$

Subarbusto a arbusto $0,15-0,4(-1,5) \mathrm{m}$ alt.; tricomas tectores nos ramos, folhas, flores e frutos, alvos, tricomas glandulares ausentes, glândulas clavadas ou capitadas diminutas nos ramos, folhas e cálice, rubro-nigrescentes; ramos pubescentes a tomentelos, glândulas frequentemente esparsas, catáfilos persistentes. Folhas subcoriáceas a coriáceas, limbo obovado 
a oblanceolado, raro elíptico, $0,6-3,4 \times 0,3-1,2$ $\mathrm{cm}$, ápice arredondado a agudo, mucronulado, glândula apical subglobosa, base aguda, margem plana a ligeiramente revoluta, serrilhada da base até o ápice, ambas as faces glabras ou esparsamente pubescentes principalmente na nervura principal, glândulas esparsamente dispostas em todo o limbo na face abaxial. Racemo axilar ou panícula terminal, raque 0,6-2,6 cm compr., densamente pubescente a tomentela; brácteas ovaladas a rômbicas, bractéolas filiformes. Pedicelo 3-5 $\mathrm{mm}$ compr.; cálice 1-3 mm compr., glabro ou pubescente juntamente com o hipanto, lobos do cálice ciliados e com glândulas esparsas; corola 5-10 mm compr., branca ou rosada nos ângulos, campanulada ou cilíndrica, glabra. Nuculânio 3-4 mm diâm., avermelhado, depresso-ovóide, costado, glabro ou esparsamente pubescente.

Material selecionado: Alegre, 3.III.1959, fl., H.S. Irwin 2794 (NY). Dores do Rio Preto, Parque Nacional do Caparaó, 20.X.2012, fl., T.B. Flores et al. 1316 (ESA, MBML, RB, UEC, VIES). Iúna, Parque Nacional do Caparaó, entre Terreirão e Arrozal, 18.II.2000, fl. e fr., V.C. Souza et al. 23384 e 23386 (ESA, GFJP). Sem município, Serra do Caparaó, Pico Luiz Inácio, 31.X.1947, fl., A.X. Moreira 45 (typus-R, L, LIL).

Material adicional examinado: BRASIL. MINAS GERAIS: Alto Caparaó, Parque Nacional do Caparaó, entre Tronqueira e Pico da Bandeira, 11.IV.2010, fl. e fr., G.O. Romão et al. 2724 e 2731 (ESA, HUEFS, MBM, RB, SPF, UEC). Espera Feliz, Parque Nacional do Caparaó, Macieira, 27.V.1999, fl. e fr., W. Forster \& L. Leoni 62 (ESA). Serra do Caparaó, Casa Queimada, 14.XI.1960, fl. e fr., A. Castellanos 22778 (GUA, L).

Gaylussacia caparoensis ocorre somente no limite entre os estados de Minas Gerais e Espírito Santo, sendo endêmica da Serra do Caparaó. No Espírito Santo é encontrada em áreas de campos de altitude, entre altitudes de 1.780-2.890 m. Essa espécie é facilmente distinta das demais do gênero por apresentar ramos velhos desfolhados com catáfilos persistentes e desenvolvidos, além da margem das folhas serrilhada da base ao ápice e corola geralmente branca e campanulada.

Ilustrações em Romão \& Souza (2003) e Romão (2011).

3.3. Gaylussacia densa Cham., Linnaea 8: 496. 1833.

Fig. 4

Subarbusto a arbusto $0,3-1(-2,5) \mathrm{m}$ alt.; tricomas tectores nos ramos, folhas, flores e frutos, alvos, tricomas glandulares ausentes, glândulas clavadas ou capitadas diminutas nas folhas e flores, rubro-amareladas; ramos pubescentes a tomentosos, catáfilos precocemente decíduos. Folhas subcoriáceas, limbo elíptico a obovado, $0,5-1,7 \times 0,3-0,9 \mathrm{~cm}$, ápice arredondado a agudo, mucronulado, glândula apical espesso-calosa, base aguda a arredondada, margem ligeiramente revoluta, inteira ou subcrenulada próximo do ápice, ambas as faces glabras ou esparsamente pubescentes principalmente na nervura principal, glândulas esparsamente dispostas em todo o limbo na face abaxial. Racemo axilar ou panícula terminal, raque $0,9-1,6 \mathrm{~cm}$ compr., densamente pubescente a tomentoso, glândulas esparsas; brácteas obovadas a rômbicas, bractéolas lineares. Pedicelo 1-2 mm compr.; cálice 1-3 mm compr., lobos do cálice ciliados, glândulas esparsas no hipanto e margem dos lobos; corola 4-6 mm compr., branca, tubulosourceolada, glabra ou esparsamente pubescente nos ângulos, geralmente glândulas esparsas. Nuculânio 2-3 mm diâm., esverdeado, subgloboso, costado, pubescente e glanduloso.

Material selecionado: Castelo, Parque Estadual Forno Grande, 10.VII.2004, fl., L. Kollmann 6846 (MBML). São Roque do Canaã, Alto Misterioso, 20.III.2007, fl., C. Esgario 145 (MBML).

Material adicional examinado: BRASIL. MINAS GERAIS: Alto Caparaó, Parque Nacional do Caparaó, trilha Tronqueira-Terreirão, 22.VII.2006, fl. e fr., G.O. Romão \& A.P.T. Dantas 1478, 1480 e 1481 (ESA, G, K, L, UEC). Espera Feliz, Parque Nacional do Caparaó, Macieira, 2011, fl., G.H. Shimizu \& M. Monge 547 (ESA, UEC). Serra do Caparaó, 9.IX.1941, fl., A.C. Brade 16892 (ESA, RB, UEC).

Gaylussacia densa está distribuída no domínio do Cerrado na Cadeia do Espinhaço em Minas Gerais e Bahia, adentrando pelas regiões de maiores altitudes da Floresta Atlântica na Serra do Caparaó em Minas Gerais e Espírito Santo e na Serra da Mantiqueira em São Paulo. No Espírito Santo é encontrada em áreas de afloramentos rochosos dos campos de altitude da Serra do Caparaó e da região do Forno Grande, entre 1.600-2.400 m. Essa espécie é amplamente variável quanto ao indumento da planta e tamanho das folhas. Sleumer (1967) e Kinoshita \& Romão (2012) reconhecem três variedades com base no tamanho da corola e indumento dos ramos, folhas e flores. No Espírito Santo é encontrada apenas Gaylussacia densa var. densa, que se caracteriza por apresentar corola 4-6 mm de comprimento e glabra ou com indumento esparso nos ângulos, além de ramos pubescentes a tomentosos e folhas glabras a esparsamente pubescentes. No aspecto geral da planta, os espécimes de Gaylussacia densa var. densa provenientes da Serra do Caparaó-MG/ 
ES assemelham-se a G. pruinosa Loes. que é endêmica da Serra dos Órgãos-RJ, como observado por Romão \& Souza (2003) e Romão (2011). Diferem quanto à disposição e consistência das folhas, além de coloração da corola, visto que $G$. densa var. densa possui folhas não imbricadas, subcoriáceas e corola branca ou rosada, enquanto que G. pruinosa apresenta folhas imbricadas, coriáceas e corola vermelha.

Ilustrações em Kinoshita-Gouvêa (1980), Silva \& Cervi (2006), Romão (2011), Kinoshita \& Romão (2012) e Cabral et al. (2016a).

3.4. Gaylussacia fasciculata Gardn., Lond. J. Bot. 4: 131.1845.

Fig. 4

Arbusto 1-1,5 m alt.; tricomas tectores nos ramos, folhas e flores, alvos, tricomas glandulares ausentes, glândulas clavadas diminutas nas folhas e flores, rubro-nigrescentes; ramos glabros a esparsamente pubescentes nos râmulos, catáfilos precocemente decíduos. Folhas cartáceas, limbo obovado, 1,6-7 × 0,7-4,2 cm, ápice arredondado a agudo, raro emarginado, mucronulado, glândula apical depresso-capitada, base aguda ou raramente obtusa, margem ligeiramente revoluta, inteira ou subcrenulada próximo do ápice, ambas as faces glabras ou pubescentes apenas na base da nervura principal, glândulas esparsamente dispostas em todo o limbo na face abaxial. Racemo axilar, raque 1,6-4 cm compr., glabra ou esparsamente tomentela, glândulas esparsas; brácteas foliáceas, elípticas a rômbicas, bractéolas filiformes. Pedicelo 2-4 mm compr.; cálice 1-2 mm compr., lobos do cálice ciliados, glândulas esparsas no hipanto; corola 4-5 mm compr., branca, urceolada, glabra. Nuculânio 3-4 mm diâm., esverdeado, depressogloboso, costado, glabro.

Material examinado: Cachoeiro do Itapemirim, Morro do Sal, 28.II.1965, fl. e fr., E. Pereira 9871 (ESA, HB). Vargem Alta, Morro do Sal, 20.V.1984, fl. e fr., V.F. Ferreira 3376 e 3390 (GUA).

Gaylussacia fasciculata está distribuída nas regiões de maiores altitudes no domínio da Floresta Atlântica, entre a Serra do Itatiaia no Rio de Janeiro e o Morro do Sal no Espírito Santo, adentrando pela Serra da Mantiqueira em Minas Gerais. No Espírito Santo é encontrada em áreas de campos de altitude na região do Morro do Sal. No aspecto geral das folhas, essa espécie assemelha-se bastante com Gaylussacia brasiliensis, mas difere principalmente quanto à coloração da corola, visto que $G$. fasciculata possui corola branca enquanto G. brasiliensis apresenta corola vermelha a rosada.
Observa-se que os espécimes provenientes do Espírito Santo apresentam corola glabra, enquanto que o material proveniente de outras localidades possui corola geralmente pubescente nos ângulos.

Ilustrações em Romão (2011) e Mezabarba et al. (2013).

3.5. Gaylussacia pallida Cham., Linnaea 8: 499. 1833. Figs. 1m,n; 4

Subarbusto a arbusto $0,3-1,5 \mathrm{~m}$ alt.; tricomas tectores nos ramos, folhas, flores e frutos, incanos, tricomas glandulares ausentes, glândulas clavadas ou capitadas diminutas nas folhas, raque da inflorescência e flores, rubro-amareladas; ramos densamente setosos a vilosos, catáfilos geralmente persistentes. Folhas subcoriáceas, limbo elíptico a obovado, 0,9-3,7 × 0,5-1,4 cm, ápice arredondado a agudo, mucronulado, glândula apical espessorecurvada, base obtusa a aguda ou atenuada, margem ligeiramente revoluta, subcrenulada próximo do ápice, face adaxial pubescente a vilosa, mais densamente na nervura principal, glândulas esparsamente dispostas em todo o limbo e margens, face abaxial densamente setosa a vilosa. Racemo axilar ou panícula terminal, raque $1-3,4 \mathrm{~cm}$ compr., densamente tomentoso a viloso, glândulas esparsas; brácteas ovaladas, elípticas ou rômbicas, bractéolas lineares. Pedicelo 2-4 mm compr.; cálice 1-3 mm compr., setoso a viloso juntamente com o hipanto, geralmente glândulas esparsas; corola 6-11 mm compr., branca ou rosada, tubuloso-campanulada a largamente campanulada, pubescente nos ângulos. Nuculânio 3-4 mm diâm., arroxeado, depressogloboso, costado, setoso a viloso.

Material examinado: Castelo, Parque Estadual Forno Grande, 5.IX.2004, fl., L. Kollmann 7007 (MBML). Iúna, Parque Nacional do Caparaó, Arrozal e arredores do Rio Claro, 18.II.2000, fl. e fr., V.C. Souza et al. 23338 (ESA, GFJP).

Material adicional examinado: BRASIL. MINAS GERAIS: Alto Caparaó, Parque Nacional do Caparaó, Trilha Tronqueira-Pico da Bandeira, 11.IV.2010, fl. e fr., G.O. Romão et al. 2723 (ESA, RB, SPF, UEC). Parque Nacional do Caparaó, 29.IX.1995, fl., L.S. Leoni 3083 (GFJP, UEC). Alto Caparaó, Parque Nacional do Caparaó, Trilha Tronqueira-Pico da Bandeira, 11.IV.2010, fl. e fr., G.O. Romão et al. 2723 (ESA, RB, SPF, UEC).

Gaylussacia pallida está distribuída no centro-sul da Cadeia do Espinhaço em Minas Gerais e na Serra do Caparaó em Minas Gerais e Espírito Santo. No Espírito Santo é encontrada nos afloramentos rochosos dos campos de altitude na Serra do Caparaó, entre 1.800-2.890 m. Essa 
espécie é distinta das demais do gênero por apresentar indumento incano, ramos setosos a vilosos e folhas em geral vilosas, além de margem das folhas ligeira a fortemente revoluta e glândula apical recurvada. De acordo com Romão \& Souza (2003) e Romão (2011), o material proveniente da Serra do Caparaó possui folhas mais largas e elípticas, com margem ligeiramente revoluta, enquanto que o material proveniente da Cadeia do Espinhaço apresenta folhas mais estreitas, chegando até linear-oblanceoladas, além de margem fortemente revoluta.

Ilustrações em Romão (2011).

3.6. Gaylussacia pulchra Pohl, Pl. Bras. 2: 41. t.127. 1831.

Figs. 1o; 4

Arbusto 1,5-8 m alt.; tricomas tectores e glandulares nos ramos, folhas, flores e frutos, alvos, glândulas clavadas diminutas nas folhas, nigrescentes; ramos esparsamente pubescentes, geralmente tomentoso-glandulares. Folhas coriáceas, limbo elíptico, 1,9-4,1 × 0,8-1,5 cm, ápice arredondado ou obtuso, mucronulado, glândula apical espesso-achatada, base aguda ou obtusa, margem ligeira a fortemente revoluta, inteira ou serrilhada próximo ao ápice, face adaxial bulada, ambas as faces pubescentes a tomentosas e geralmente tomentoso-gladulares, mais densamente nas nervuras, frequentemente glândulas esparsamente dispostas em todo o limbo na face abaxial. Racemo axilar subapical, raque 1,7-2,1 cm compr., densamente pubescenteglandular; brácteas lanceolada ou oblanceolada, bractéolas filiformes. Pedicelo 3-6 mm compr.; cálice 1-2 mm compr., pubescente e geralmente híspido-glandular nos bordos dos lobos como no hipanto; corola 5-7 mm compr., vermelha a rosada, urceolada, esparsamente pubescente nos ângulos. Nuculânio ca. 3 mm diâm., negro-avermelhado, depresso-ovoide, pubescente a viloso.

Material examinado: Castelo, Forno Grande, 13.V.1949, fl., A.C. Brade 19818 (G, L, RB, S, UEC). Domingos Martins, Pedra do Colono e das Flores, 14.VIII.1999, fl., J.M.L. Gomes 2589 (VIES).

Material adicional examinado: BRASIL. MINAS GERAIS: São Gonçalo do Rio Preto, Parque Estadual do Rio Preto, córrego Capão Azul, 24.IV.2006, fl., E.B. Foresto et al. 257 (ESA, SPF). Parque Estadual do Ibitipoca, XII.1970, fl. e fr., P.L. Krieger (CESJ 9462, MBM 277091).

Gaylussacia pulchra está distribuída principalmente no domínio do Cerrado ao longo da Cadeia do Espinhaço em Minas Gerais e Bahia, adentrando pela Floresta Atlântica no Espírito
Santo e na Serra do Ibitipoca em Minas Gerais. No Espírito Santo é encontrada em áreas de campos na região de Forno Grande e Domingos Martins, em altitudes em torno de $1.000 \mathrm{~m}$. Essa espécie caracteriza-se por apresentar folhas com a face adaxial bulada e margem em geral fortemente revoluta, além da presença de tricomas glandulares, embora seja comumente confundida com $G$. brasiliensis por sua semelhança no aspecto geral da planta e corola vermelha e urceolada, anteriormente discutido.

Ilustrações em Pohl (1831), Romão et al. (2004) e Romão (2011).

3.7. Gaylussacia rugosa Cham. \& Schltdl., Linnaea 1: 534.1826.

Fig. 4

Arbusto ca. 2,5 m alt.; tricomas tectores e glandulares nos ramos, folhas, flores e frutos, alvos a ferrugíneos, glândulas clavadas diminutas nas folhas, nigrescentes; ramos densamente pubescentes a tomentosos e híspido-glandulares. Folhas rigidamente coriáceas, limbo elíptico a ovalado, 2,9-6,3 × 1,5-2,6 cm, ápice arredondado, emarginado, mucronulado, glândula apical espessoachatada, base arredondada ou obtusa, margem ligeiramente revoluta, inteira, face adaxial não bulada, ambas as faces tomentosas a velutinas e híspido-gladulares, mais densamente nas nervuras, glândulas esparsamente dispostas em todo o limbo na face abaxial. Racemo axilar, raque 3,9-9,2 cm compr., densamente tomentosa e híspido-glandular; brácteas foliáceas, elípticas a rômbicas, bractéolas filiformes. Pedicelo 2-3 mm compr.; cálice 4-5 $\mathrm{mm}$ compr., tomentoso e híspido-glandular como no hipanto; corola 8-10 $\mathrm{mm}$ compr., branca, tubuloso-urceolada, tomentosa e viloso-glandular nos ângulos. Nuculânio 4-6 mm diâm., negro, globoso, liso ou ligeiramente costado, tomentoso e híspido-glandular.

Material examinado: Domingos Martins, Pedra Azul, rodovia Vitória-Belo Horizonte Km 89, 16.VI.1989, fl., G.J. Shepherd 453 (UEC, VIES).

Material adicional examinado: BRASIL. MINAS GERAIS: Santa Bárbara, Parque Natural da Serra do Caraça, trilha para Gruta de Lourdes, 6.IX.2007, fl., G.O. Romão \& A.P.T. Dantas 2248, 2249, 2250 e 2251 (ESA). Santo Antônio do Itambé, Pico do Itambé, 26.II.2002, fr., G.O. Romão et al. 856 (ESA).

Gaylussacia rugosa está distribuída no domínio do cerrado na região centro-sul da Cadeia do Espinhaço em Minas Gerais, ocasionalmente adentrando pela Floresta Atlântica no Espírito Santo. No Espírito Santo é encontrada em áreas de campos nas redondezas da Pedra Azul. Quanto ao 
aspecto geral da planta e indumento-glandular (pubescentes a tomentosos e híspido-glandulares) dos ramos e folhas, essa espécie aproxima-se $G$. setosa Kin.-Gouv. e G. rupestris G.O. Romão \& V.C. Souza, que ocorrem na Cadeia do EspinhaçoBA/MG. Em geral, Gaylussacia rugosa apresenta folhas com margem ligeiramente revoluta, ápice emarginado e face abaxial com tricomas tectores e glandulares, enquanto que $G$. setosa se difere por possuir folhas com margem plana e apenas tricomas glandulares na face abaxial, e $G$. rupestris se difere pelas margens das folhas revolutas na base e ápice agudo a obtuso.

Ilustrações em Meisner (1863) e Romão (2011).

\section{Referências}

Amaral MCE, Bittrich V, Faria AD, Anderson LO \& Aona LYS (2008) Guia de campo para plantas aquáticas e palustres do estado de São Paulo. Holos Editora, Ribeirão Preto. 452p.

BFG - The Brazil Flora Group (2015) Growing knowledge: an overview of seed plant diversity in Brazil. Rodriguésia 66: 1085-1113.

Cabral A, Romão GO, Roman SA \& Menini Neto L (2016a) Ericaceae da Serra Negra, Minas Gerais, Brasil. Rodriguésia 67: 225-236.

Cabral A, Romão GO, Salimena FRG \& Menini Neto L (2016b) Ericaceae do Parque Estadual da Serra do Papagaio, Minas Gerais, Brasil. Boletim de Botânica da Universidade de São Paulo 34: 7-19.

Coelho RLG, Romão GO \& Souza VC (2010) Levantamento das espécies de Ericaceae, Orobanchaceae e Plantaginaceae da Reserva Natural da Vale do Rio Doce, Linhares-ES. Pabstia 21: 10-38.

Dutra VF, Alves-Araújo A \& Carrijo TT (2015) Angiosperm checklist of Espírito Santo: using electronic tools to improve the knowledge of an Atlantic Forest biodiversity hotspot. Rodriguésia 66: 1145-1152. [supplementary material: 92-93].

Garbin ML, Saiter FZ, Carrijo TT \& Peixoto AL (2017) Breve histórico e classificação da vegetação capixaba. Rodriguésia 68: 1883-1894.

Gonçalves EG \& Lorenzi H (2007) Morfologia vegetal: organografia e dicionário ilustrado de morfologia das plantas vasculares. Instituto Plantarum, Nova Odessa. 416p.

Harris JG \& Harris MW (2003) Plant identification terminology: an illustrated glossary. $2^{\mathrm{a}} \mathrm{ed}$. Spring Lake Publ., Spring Lake. 216p.

Hijmans RJ, Guarino L, Bussink C, Mathur P, Cruz M, Barrantes I \& Rojas E (2004) DIVA-GIS. Version 7.5. A geographic information system for the analysis of species distribution data. Disponível em < http://www.diva-gis.org/download $>$. Acesso em 17 junho 2017.

Judd WS (1984) A taxonomic revision of the American species of Agarista (Ericaceae). Journal of the Arnold Arboretum 65: 255-342.

Judd WS (1995) Agarista G. Don. In: Luteyn JL, Judd WS, Clemants SE, Diggs GM, Sørensen PD, Dorr LJ \& Wallace GD (eds.) Ericaceae - part II. The superior ovaried genera. Flora Neotropica Monograph 66: 295-344.

Judd WS, Campbell CS, Kellogg EA, Stevens PF \& Donoghue MJ (2008) Plant systematics, a phylogenetic approach. $3^{\text {a }}$ ed. Sinauer Associates, Sunderland. 612p.

Kinoshita-Gouvêa LS (1980) Estudos taxonômicos e fitogeográficos da família Ericaceae no Brasil. Tese de Doutorado. Universidade de São Paulo, São Paulo. 319p.

Kinoshita LS (1995) Ericaceae. In: Stannard BL, Harvey YB \& Harley RM (eds.) Flora of the Pico das Almas, Chapada Diamantina-Bahia, Brazil. Royal Botanical Gardens, Kew. Pp. 291-296.

Kinoshita LS \& Romão GO (2010) Ericaceae. In: Forzza RC et al. (eds.) Catálogo de plantas e fungos do Brasil. Vol. 2. Andrea Jakobsson Estúdio, Instituto de Pesquisa Jardim Botânico do Rio de Janeiro, Rio de Janeiro. Pp. 934-937. Disponível em <http://floradobrasil.jbrj.gov. br/2010/FB017330>. Acesso em 10 janeiro 2017.

Kinoshita LS \& Romão GO (2011) Ericaceae. In: Cavalcanti TB \& Silva AP (eds.) Flora do Distrito Federal, Brasil. Vol. 9. Embrapa Recursos Genéticos e Biotecnologia, Brasília. Pp. 115-127.

Kinoshita LS \& Romão GO (2012) Ericaceae. In: Wanderley MGL, Shepherd GJ, Melhem TS, Giulietti AM \& Martins SE (eds.) Flora fanerogâmica do estado de São Paulo. Instituto de Botânica, São Paulo. Vol. 7, pp. 151-172.

Kron KA, Judd WS, Stevens PF, Crayn DM, Anderberg AA, Gadek PA, Quinn CJ \& Luteyn JL (2002) Phylogenetic classification of Ericaceae: molecular and morphological evidence. The Botanical Review 68: 335-423.

Luteyn JL (1995) Gaultheria L. In: Luteyn JL, Judd WS, Clemants SE, Diggs GM, Sørensen PD, Dorr LJ \& Wallace GD (eds.) Ericaceae - part II. The superior ovaried genera. Flora Neotropica Monograph 66: 384-488.

Luteyn JL (2002) Diversity, adaptation and endemism in Neotropical Ericaceae: biogeographical patterns in the Vaccinieae. Botanical Review 68: 55-87.

Marinero FEC, Maranho LT \& Hatschbach GG (2007) O gênero Gaultheria L. (Ericaceae) no estado do Paraná, Brasil. Revista Brasileira de Biociências 5: 615-617. 
Marques MCM (1975) Ericáceas. In: Reitz P (ed.) Flora ilustrada catarinense, parte I, fasc. ERIC. Herbário "Barbosa Rodrigues", Itajaí. 65p. est 15.

Martinelli G, Judice DM, Barros FSM \& Fernandez EP (2013) Ericaceae. In: Martinelli G \& Moraes MA (eds.) Livro vermelho da flora do Brasil. Andrea Jakobsson Estúdio, Instituto de Pesquisas Jardim Botânico do Rio de Janeiro, Rio de Janeiro. Pp. 491-495.

Meisner CF (1863) Ericaceae. In: von Martius CFP \& Eichler AG (eds.) Flora brasiliensis. Frid. Fleischer, Lipsiae. Vol. 7, pp. 119-182.

Mezabarba V, Vianna Filho MDM, Borges RAX \& Mansano VF (2013) Ericaceae do Parque Nacional do Itatiaia, RJ, Brasil. Hoehnea 40: 115-130.

Morellato LPC \& Haddad CFB (2000) Introduction: the Brazilian Atlantic Forest. Biotropica 32: 786-792.

Myers N, Mittermeyer RA, Fonseca GAB \& Kent J (2000) Biodiversity hotspots for conservation priorities. Nature 403: 853-858.

Pereira OJ \& Assis AM (2000) Florística da restinga de Camburi, Vitória, ES. Acta Botanica Brasilica 14: 99-111.

Pohl IE (1831) Plantarum Brasiliae ícones et descriptiones hactenus ineditae iussu et auspiciis. 2: 31-42.

Radford AE (1974) Fundamental of plant systematics. Harper \& Row, New York. 507p.

Ribeiro MC, Metzger JP, Martensen AC, Ponzoni FJ \& Hirota MM (2009) The Brazilian Atlantic Forest: how much is left, and how is the remaining forest distributed? Implication for conservation. Biological conservation 142: 1141-1153.

Romão GO (2009) Ericaceae. In:. Stehmann JR, Forzza RC, Salino A, Sobral M, Costa DP \& Kamino LHY (eds.) Plantas da Floresta Atlântica. Instituto de
Pesquisas Jardim Botânico do Rio de Janeiro, Rio de Janeiro. Pp.241-242.

Romão GO (2011) Revisão taxonômica de Gaylussacia Kunth (Ericaceae) e estudos da filogenia do gênero. Tese de Doutorado. Universidade Estadual de Campinas, Campinas. 497p.

Romão GO \& Souza VC (2003) Flora fanerogâmica do Parque Nacional do Caparaó: Ericaceae. Pabstia 14: 1-12.

Romão GO, Wanderley MGL \& Yokoya N (2004) Flora de Grão-Mogol, Minas Gerais: Ericaceae. Boletim de Botânica da Universidade de São Paulo 22: 97-100.

Romão GO \& Souza VC (2014) Flora da Serra do Cipó, Minas Gerais: Ericaceae. Boletim de Botânica da Universidade de São Paulo 32: 43-70.

Silva RR \& Cervi AC (2006) As Ericaceae Juss. nativas no estado do Paraná, Brasil. Acta Biológica Paranaense 35: 1-45.

Sleumer H (1959) Studien über die Gattung Leucothoe D. Don. Botanische Jahrbücher für Systematik 78: 435-480.

Sleumer H (1967) Die gattung Gaylussacia H.B.K. Botanische Jahrbücher für Systematik 86: 309-384.

Souza VC \& Lorenzi H (2008) Botânica sistemática: guia ilustrado para identificação das famílias de Angiospermas da flora brasileira, baseado em APG II. Instituto Plantarum, Nova Odessa. 640p.

Stevens PF (1971) A classification of the Ericaceae: subfamilies and tribes. Botanical Journal of the Linnean Society 64: 1-53.

Thiers B [continuamente atualizado] Index Herbariorum: a global directory of public herbaria and associated staff. New York Botanical Garden's Virtual Herbarium. Disponível em <http://sweetgum.nybg. org/ih/>. Acesso em 10 janeiro 2017.

\footnotetext{
Lista de exsicatas

Andrade RC 37 (3.1.1). Angeli C 219 (3.2). Assis AM 344 (3.1.1), 475 (3.1.1), 577 (1.2), 2852 (3.1.1). Bianchi RC 2 (3.1.1), 18 (3.1.1). Brade AC 16892 (3.3), 16908 (3.2), 17126 (2.1), 19273 (2.1), 19818 (3.6), 19872 (3.3). Braga JMA 4664 (3.2). Brügger MC 22911 (2.1), FPNC 337 (2.1), FPNC 338 (1.1.2). Carvalho S 17 (3.1.1). Castellanos A 22778 (3.2). Couto DR 369 (2.1). Dutra SS 128 (3.1.1), 313 (3.1.1). Esgario C 58 (2.1), 145 (3.3), 146 (2.1), 165 (2.1). Farias GL 75 (3.1.1), 79 (1.2), 571 (3.1.1). Farney C 4766 (1.2), 4775 (3.1.1). Ferreira VBR 11 (3.1.1). Ferreira VF 3376 (3.4), 3390 (3.4). Flaster B 107 (3.2). Flores TB 1237 (3.1.1), 1316 (3.2). Folli DA 568 (3.1.1), 601 (1.2), 1959 (1.2), 4033 (1.2). Fontana AP 889 (2.1), 1041 (3.3), 1584 (2.1), 2214 (2.1). Foresto EB 257 (3.6). Forster, W 62 (3.2), 63 (2.2.2), 72 (2.1), 111 (1.1.2), 792 (1.1.2). Giaretta, AO 80 (1.2), 1079 (1.2). Gomes JML 85 (3.1.1), 896 (3.1.1), 1344 (3.1.1), 2589 (3.6), 3407 (3.1.1). Hatschbach G 31470 (2.1), 46891 (2.1), 71391 (2.1), 71397 (3.1.1). Irwin HS 2764 (2.2.1), 2794 (3.2). Kollmann L 6846 (3.3), 7007 (3.5), 7158 (2.1), 8128 (2.1), 9315 (1.1.1), 9352 (2.1), 10158 (2.1). Krieger L CESJ 9462 (3.6), CESJ 14161 (3.2), CESJ 14170 (2.2.1), CESJ 19560 (3.1.1), CESJ 20463 (1.2), CESJ 20764 (3.1.1), CESJ 22561
} 
(2.1), CESJ 23233 (2.2.2), CESJ 23236 (2.1), CESJ 24004 (1.1.1), CESJ 24043 (2.2.1), MBM 277091 (3.6), FPNC 250 (3.2), FPNC 412 (3.5), FPNC 549 (3.5), FPNC 856 (1.1.1), FPNC 992 (3.2). Kuhlmann JG 176 (3.1.1). Kuntz J 616 (3.2), 619 (3.2), 623 (2.2.2), 625 (3.2), 626 (2.2.2). Leal TVS VIES 336 (3.1.1). Leoni LS 1192 (2.2.2), 2036 (3.3), 2686 (1.1.1), 3074 (1.1.1), 3083 (3.5), 3458 (3.2), 4063 (3.5), 4199 (3.2), 4520 (3.5). Lima HC 1710 (3.1.1). Lima JCA 6 (3.1.1). Lobo B R 92733 (3.2), R 92749 (3.2), R 92750 (3.2), R 92772 (3.2). Lombardi JA 931 (3.5), 934 (1.1.1). Lopes LCM 36 (3.1.1). Lorencini TS 290 (3.1.1), 335 (2.1). Lorenzi, H 5506 (3.2). Lube GGK 143 (1.2). Lucas EJ 985 (3.1.1). Lutz A 1207 (3.2). Lutzelburg 7156 (3.1.2). Magnago LFS 1389 (1.1.1). Maielo-Silva 87 (1.2). Manhães VC 370 (2.2.2). Martinelli G 10996 (3.1.1), 11013 (3.1.1). Martins RFA 37 (3.1.1), 154 (3.1.1). Mattos J HAS 81150 (3.1.1). Mazine FF 165 (1.1.2). Meirelles J 576 (3.1.1), 579 (1.2). Miranda EB 660 (3.1.1). Moreira AX 45 (3.2). Pereira E 9871 (3.4). Pereira OJ 1 (1.2), 2 (3.1.1), 5 (3.1.1), 18 (1.2), 22 (1.2), 132 (3.1.1), 262 (3.1.1), 311 (2.1), 456 (2.1), 944 (1.2), 945 (3.1.1), 1722 (3.1.1), 2173 (3.1.1), 2803 (3.1.1), 2924 (3.1.1), 2997 (1.2), 3165 (1.2), 3181 (3.1.1), 3511 (3.1.1), 3632 (1.2), 3641 (3.1.1), 3783 (3.1.1), 3992 (3.1.1), 4069 (3.1.1), 4245 (3.1.1), 4449 (3.1.1), 4655 (3.1.1), 4685 (1.2), 4792 (3.1.1), 5289 (3.1.1), 5331 (3.1.1), 5598 (3.1.1), 5858 (3.1.1), 6109 (3.1.1). Ribeiro M 10 (1.2). Ribeiro R 516 (3.1.1). Romão GO 856 (3.7), 1254 (3.1.1), 1474 (3.2), 1475 (3.2), 1476 (3.5), 1477 (3.5), 1478 (3.3), 1479 (3.5), 1480 (3.3), 1481 (3.3), 1482 (2.1), 1483 (2.2.2), 1484 (2.2.1), 1485 (1.1.1), 1486 (3.2), 1488 (3.3), 2248 (3.7), 2249 (3.7), 2250 (3.7), 2251 (3.7), 2710 (2.1), 2723 (3.5), 2724 (3.2), 2730 (2.2.1), 2731 (3.2). Sazima M 14054 (1.2). Schwacke R 93020 (3.2). Shepherd GJ 453 (3.7), 5766 (2.1), 5786 (2.2.2), 5794 (3.2), 5802 (3.5), 9235 (3.2), FPNC 5799 (1.1.1). Shimizu G 547 (3.3). Silva AS 1981 (3.1.1). Simão- Bianchini R 225 (1.1.1). Siqueira GS 57 (3.1.1). Sobral M 4061 (3.1.1). Souza AB 18 (3.2), 45 (3.2), 90 (2.1). Souza JP 2125 (2.2.2), 5735 (3.1.1), 6044 (3.1.1). Souza VC 12153 (2.2.2), 12171 (2.2.1), 12172 (3.2), 12197 (3.2), 23330 (2.2.1), 23338 (3.5), 23384 (3.2), 23393 (1.1.2), 23407 (3.5), 23412 (2.2.1), 23526 (1.1.2), 26980 (3.2). Sucre D 8634 (1.2). Sydney \& Rita 15108 (2.2.1). Tinti BV VIC 42138 (2.1). Vall O RB 243184 (2.1). Vinha PC 1262 (3.1.1). Weinberg B 400 (2.1). Zikan 2184 (3.2). Zorzanelli JPF 156 (2.1). Sem coletor “344” CH 3237 (3.1.1). 
